\title{
Real-World Efficacy and Safety of Apremilast in Belgian Patients with Psoriatic Arthritis: Results from the Prospective Observational APOLO Study
}

\author{
Kurt de Vlam • Adrien Nzeusseu Toukap · Marie-Joëlle Kaiser • \\ Johan Vanhoof · Philip Remans · Marthe Van den Berghe · \\ Silvana Di Romana $\cdot$ Filip Van den Bosch $\cdot$ Rik Lories
}

Received: September 29, 2021 / Accepted: December 3, 2021 / Published online: January 3, 2022

(C) The Author(s) 2021

\section{ABSTRACT}

Introduction: Apremilast is approved for the treatment of psoriasis and psoriatic arthritis (PsA). Real-world evidence on the efficacy and safety of apremilast in clinical practice is limited. We assessed the use of apremilast in patients with PsA in Belgium clinical practice.

Methods: The multicentre, observational, prospective APOLO study enrolled patients with active PsA initiating apremilast in Belgium

Supplementary Information The online version contains supplementary material available at https:// doi.org/10.1007/s12325-021-02016-x.

K. de Vlam · R. Lories $(\bowtie)$

Division of Rheumatology, University Hospitals

Leuven, KU Leuven, Leuven, Belgium

e-mail: Rik.Lories@kuleuven.be

K. de Vlam · R. Lories

Department of Development and Regeneration, Skeletal Biology and Engineering Research Center, KU Leuven, Leuven, Belgium

A. N. Toukap

Department of Rheumatology, Saint-Luc University

Hospital, Brussels, Belgium

M.-J. Kaiser

Department of Rheumatology, GIGA Research, CHU

Liège, Liège, Belgium

J. Vanhoof · P. Remans

Department of Rheumatology, ReumaClinic Genk, Genk, Belgium between April 2017 and December 2018. Primary outcome was PsA Response Criteria (PsARC) after 6 months of apremilast treatment. Secondary outcomes included PsA Impact of Disease 12 (PsAID12) and Health Assessment Questionnaire Disability Index (HAQ-DI). Disease-specific outcomes and patient-reported outcomes (PROs) were analysed for patients who received apremilast within 30 days prior to their study inclusion and completed at least 150 days of treatment (reference set [REF]).

Results: Of 107 patients enrolled in the study, 106 received at least one dose of apremilast and 69 were included in the REF. PsARC response

\author{
M. Van den Berghe \\ Department of Rheumatology, ASZ Aalst, Aalst, \\ Belgium \\ S. Di Romana \\ Department of Rheumatology, University Hospital \\ Saint-Pierre, Brussels, Belgium \\ F. Van den Bosch \\ Department of Rheumatology, Ghent University \\ Hospital, Ghent, Belgium
}


was achieved by $43.5 \%$ of patients $(30 / 69)$ in the REF at month 6; mean global and composite scores including 68-joint count for pain/tenderness (68-TJC) and 66-joint count for swelling (66-SJC) improved, and $27 \%$ and $42 \%$ of patients with 68-TJC and 66-SJC $>0$ at baseline had complete joint count resolution, respectively. Mean global and composite PsAID12 and HAQ-DI scores decreased at 6 months, indicating improved quality of life. Apremilast was well tolerated and the reported adverse events were in line with the known safety profile.

Conclusion: Results from the APOLO study indicate that treatment with apremilast in Belgian clinical practice improves the signs and symptoms of PsA as well as patient quality of life.

\section{Clinicaltrials.gov Identifier: NCT03096990.}

Keywords: Apremilast; Psoriatic arthritis; Patient-reported outcome; Real-world evidence

\section{Key Summary Points}

Why carry out this study?

Data on the real-world effectiveness and tolerability of apremilast for treatment of psoriatic arthritis are limited.

This prospective observational study assessed the effectiveness and safety of apremilast for the treatment of active psoriatic arthritis in Belgian clinical practice.

What was learned from the study?

Nearly half of patients achieved Psoriatic Arthritis Response Criteria after 6 months of treatment with apremilast. Apremilast also improved PROs and disease-specific measures including Health Assessment Questionnaire Disability Index, Psoriatic Arthritis Impact of Disease 12 Questionnaire and enthesitis and dactylitis scores.

Apremilast was well tolerated, and no new safety signals were identified.
Our results indicate that apremilast improves the signs and symptoms of psoriatic arthritis as well as patient quality of life in Belgian clinical practice.

\section{INTRODUCTION}

Psoriatic arthritis (PsA) is a chronic, progressive, inflammatory joint disease, which affects $0.05-0.25 \%$ of the global population and an estimated $6-42 \%$ of patients with psoriasis [1-4]. PsA significantly impairs all aspects of patients' life, including physical and emotional aspects, social activities and social participation [5]. While the pathogenesis of PsA is complex and multifactorial, and is still not fully understood, genetic, environmental and immunological factors are thought to play an important role $[6,7]$. The articular and dermatological manifestations of PsA are heterogeneous and include peripheral arthritis, axial inflammation, enthesitis, dactylitis and skin and nail involvement/symptoms, which can be difficult to treat [8]. Moreover, progressive joint damage, increasing disability and accelerated atherosclerosis, increased cardiovascular morbidity and early mortality are associated with severe PsA [9-11].

PsA is a heterogeneous disease and several treatments are available to control the different disease manifestations [12]. Apremilast was approved by the US Food and Drug Administration in 2014 for the management of PsA in adults and for moderate or severe plaque psoriasis in patients who were candidates for phototherapy or systemic therapy [13-15]. It was then approved in Europe in 2015 for the treatment of active PsA, alone or in combination with conventional synthetic disease-modifying anti-rheumatic drugs (csDMARDs) in adult patients presenting inadequate response or intolerant to prior csDMARD therapy. Apremilast is also approved for the treatment of moderate to severe chronic plaque psoriasis in adult patients (at least 18 years of age) who fail to respond to, who have a contraindication for, or 
are intolerant to other systemic therapy including cyclosporine, methotrexate or psoralen and ultraviolet A light [16].

In 2015, the Group for Research and Assessment of Psoriasis and Psoriatic Arthritis (GRAPPA) updated their recommendations for the management of PsA [17]. GRAPPA recognised the following six disease domains that should be addressed therapeutically for the treatment of PsA: (1) peripheral arthritis; (2) axial disease; (3) enthesitis; (4) dactylitis; (5) skin disease; (6) nail disease. Moreover, they developed treatment recommendations and evaluated the strength of the recommendations for each available therapy ('strong' or 'conditional'), using the Grading of Recommendations, Assessment, Development and Evaluation. Apremilast received a strong recommendation by GRAPPA for patients with peripheral arthritis unresponsive to csDMARDs and a conditional recommendation for patients with peripheral arthritis who were DMARDnaïve [18]. In more recent guidelines, GRAPPA also strongly recommends apremilast for various PsA disease manifestations including plaque psoriasis, enthesitis, dactylitis, nail disease, and DMARD-naïve peripheral arthritis, and conditionally recommends apremilast for peripheral arthritis with insufficient response to DMARDs [19].

APOLO was designed to provide real-world evidence on apremilast use among Belgian patients with PsA. The primary objective was to evaluate the effect of apremilast on the Psoriatic Arthritis Response Criteria (PsARC) after 6 months of treatment. Secondary objectives included evaluation of the effect of apremilast on established patient-reported outcomes (PROs), including the PsA Impact of Disease 12 (PsAID12) and the Health Assessment Questionnaire Disability Index (HAQ-DI), which are important complementary components for assessing the impact of the disease and response to therapy [20]. Additional disease-specific parameters, such as Leeds Enthesitis Index (LEI) and dactylitis, duration of treatment with apremilast and its tolerability were also assessed.

\section{METHODS}

\section{Patients}

APOLO enrolled adults diagnosed with active PsA initiating apremilast (30 mg twice daily, after a period of up-titration for 5 days) between April 2017 and December 2018 in Belgium according to local label and reimbursement criteria. Patients with hypersensitivity to apremilast or its excipients, pregnant or lactating women and women of childbearing potential not under an acceptable method of contraception were excluded. The study protocol was approved by the medical ethics committee of UZ Leuven and local independent ethics committees and written informed consent was obtained from each eligible patient before study enrolment. The study was conducted in accordance with the principles stated in the Declaration of Helsinki and Good Clinical Practice Guideline (CPMP/ICH/135/95).

\section{Study Design}

APOLO was a multicentre, prospective, observational study (ClinicalTrials.gov Identifier NCT03096990). Patients were followed up for at least 6 months and at most 18 months after apremilast initiation, using data collected at routine visits to their treating rheumatologist up to 31 December 2018 (no mandatory visits). Per local reimbursement criteria [21], response to treatment was assessed 6 months after apremilast initiation, and treatment continued for an additional 12 months if patients met the required criteria. The study was terminated early, on 31 December 2018.

\section{Study Outcomes}

The primary outcome was PsARC response 6 months after apremilast initiation. Secondary disease-specific outcomes included the LEI and dactylitis. PROs included the PsAID12 questionnaire and HAQ-DI.

PsARC is a composite of four measures: (1) 68-joint count for pain/tenderness (68-TJC); (2) 66-joint count for swelling (66-SJC); (3) Patient 
Global Assessment (PtGA) of disease activity; and (4) Physician Global Assessment (PGA) of disease activity. PsARC response was defined as improvement in at least two of these four measures, one of which must be a joint score including 68-TJC and/or 66-SJC, and no worsening in the remaining measures. Improvement in 68-TJC and 66-SJC was defined as a decrease by at least $30 \%$ in the score. PtGA and PGA of disease activity were assessed using a Likert scale $1-5$ ( $1=$ no symptoms; 5 = very strong symptoms) and improvement was defined as a decrease by one category on the Likert scale [1].

LEI quantifies joint tenderness at six pre-defined sites [22] (bilateral Achilles tendon insertions, medial femoral condyles and lateral epicondyles of the humerus; $0=$ no enthesitis; $6=$ six enthesitis). Dactylitis was assessed through the dactylitis count (range 0-20 digits).

PsAID12 assesses the disease domains of pain, fatigue, skin problems, work and/or leisure activities, functional capacity, discomfort, sleep disturbance, coping, anxiety, embarrassment, social participation and depression from the patients' perspective. Each domain has a different weight and uses a 0-10 numerical rating scale $(10=$ worst health score). Changes over time in PsAIDs were summarised for patients with a PsAID $\geq 4$ at apremilast initiation ( $4=$ cut-off value for patient-acceptable symptom state) [23].

HAQ measures health status and health-related quality of life and represents a generic, patient-centred measure of functioning and disability. HAQ consists of 20 items covering activities of daily living classified in eight domains (dressing and grooming, arising, eating, walking, hygiene, reach, grip, activities). Patients indicate whether they could perform each activity 'without any difficulty', with 'some' or 'much difficulty', or if they were 'unable to do' the activity [24]. The HAQ yields a disability index (HAQ-DI) between 0 and 3 $(0=$ no functional disability to $3=$ severe functional disability).

The safety and tolerability of apremilast were assessed by the number of treatment-emergent adverse events (TEAEs; AEs that occurred or worsened within 6 days of the patient's first dose of apremilast and up to 30 days after the last dose). TEAEs were coded using the Medical Dictionary for Regulatory Activities (MedDRA) version 22.0.

\section{Statistical Analysis}

APOLO was an observational study and therefore no formal sample size calculation was performed. A planned sample size of 150 patients was considered a meaningful cohort relative to the prescribing use of apremilast within Belgium. All analyses were descriptive in nature. Quantitative variables were reported as number of observed values, mean and standard deviation (SD). Qualitative variables were reported as absolute frequency, percentage and number of missing observations. Measurements not performed or recorded were treated as missing data and included in percentage calculations.

Disease-specific outcomes and PROs were analysed for patients who received apremilast within 30 days prior to their inclusion in the study and completed at least 150 days of treatment (reference set $[\mathrm{REF}]$ ). TEAEs were summarised for all enrolled patients who received at least one dose of apremilast (safety analysis set $[\mathrm{SAF}]$ ). All analyses were performed using the statistical analysis software version 9.4.

\section{RESULTS}

\section{Patient Disposition}

Between 21 April 2017 and 31 December 2018, 107 eligible patients were enrolled in the study. Of these, 106 (99.1\%) received at least one dose of apremilast and were included in the SAF. Sixty-nine $(65.1 \%)$ patients received apremilast within 30 days prior to their inclusion in the study and completed at least 150 days of treatment and were included in the REF (Fig. 1). One-fifth $(21 / 106$ [19.8\%]) of patients in the SAF discontinued the study before month 6 , mostly due to TEAEs (12 patients) and investigator decision (9 patients); approximately half (49/106 [46.2\%]) of the patients discontinued the study before month 18 . Therefore, we report data up to 12 months after apremilast treatment 


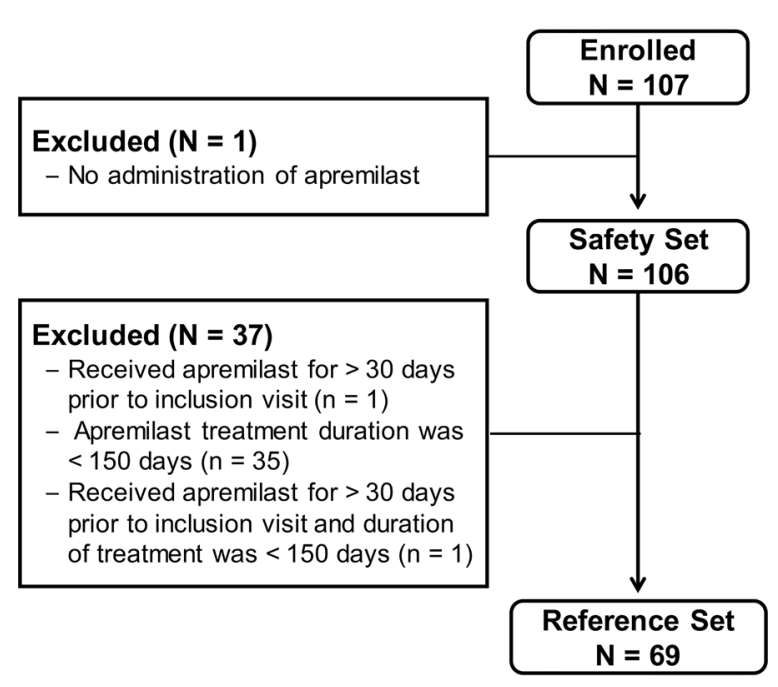

Fig. 1 Patient disposition

initiation. On study termination, 58 (54.7\%) patients in the SAF were still receiving apremilast treatment. Mean (SD) follow-up in the SAF and REF was 8.47 (4.69) and 10.70 (4.03) months, respectively.

Most patients in the SAF received apremilast for at least 6 months $(64 / 106$ [60.4\%]; status unknown for 4 patients). Nearly half (47/106 [44.3\%]) stopped apremilast within 12 months, mainly because of insufficient effectiveness (21 patients) and TEAEs (18 patients). Mean (SD) treatment duration in the SAF and REF was 4.56 (3.21) and 7.63 (2.68) months, respectively.

\section{Patient Characteristics}

Patient characteristics at apremilast initiation are summarised in Table 1. Mean (SD) age of patients in the SAF was 53 years and ranged from 24 to 79 years. The majority of patients had a concomitant diagnosis of psoriasis (82/ 106 [77.4\%]). All except 1 patient had received previous treatment for PsA, with csDMARDs $(95.3 \%)$ and non-steroidal anti-inflammatory drugs (NSAIDs; $40.6 \%$ ) being the most common prior therapies. The majority of patients in the SAF were biologic-naïve, with less than 20\% previously treated with biologic DMARDs. Approximately two-thirds (68/106 [64.2\%]) of patient in the SAF were receiving concomitant
PsA treatment at enrolment, and approximately one-quarter $(29 / 106$ [27.4\%]) received concomitant PsA medications during the study (Table S1). Almost half (49/106 [46.7\%]) of all patients were working. Few (12/56 [21.4\%]) non-working patients reported their non-working status to have an established relationship with PsA. In general, patients included in the REF were similar to those included in the SAF (Table 1).

\section{PsARC Response}

At 6 months after apremilast initiation, 30 (43.5\%) patients in the REF achieved PsARC response, $16(23.2 \%)$ were non-responders and data were missing for $23(33.3 \%)$ patients. Of the patients with non-missing data, $65.2 \%$ (30/ 46) were PsARC responders. In the SAF, 32 $(30.2 \%)$ patients achieved PsARC response at 6 months, $17(16.0 \%)$ were non-responders and data were missing for $57(53.8 \%)$ patients (Table S2a). The composite measures for PsARC response are provided in Table S3. Over half of all patients had improvements in 68-TJC and 66-SJC scores (at least 30\% decrease in score: 40/56 [71.4\%] and 44/55 [80.0\%], respectively) at month 6. Among patients with 68-TJC $>0$ and $66-$ SJC $>0$ at apremilast initiation, $26.8 \%$ $(15 / 56)$ and $41.8 \%(23 / 55)$ had complete resolution at month 6 (Fig. 2). PGA and PtGA scores were lower at month 6 compared with at apremilast initiation, indicating an overall improvement (Table S3). The percentage of patients with no symptoms $\quad($ score $=1)$ increased from $8.2 \%(5 / 61)$ and $1.6 \%(1 / 63)$ at baseline to $40.7 \%(22 / 54)$ and $21.6 \%(11 / 51)$ at month 6 for PGA and PtGA, respectively (Fig. 2). Similar trends were observed in the SAF (Table S2b; Fig. S1).

\section{Enthesitis and Dactylitis}

Improvements in enthesitis and dactylitis were observed in the REF at 6 months. Among patients with enthesitis (LEI $>0$ ) at apremilast initiation, over one-third (9/24 [37.5\%]) achieved complete resolution at month 6 . Among patients with dactylitis at baseline, 
Table 1 Patient characteristics

\begin{tabular}{|c|c|c|c|}
\hline Characteristic & & SAF $(N=106)$ & $\operatorname{REF}(N=69)$ \\
\hline \multirow[t]{2}{*}{ Age (years) } & $N$ & 106 & 69 \\
\hline & Mean $(\mathrm{SD})$ & $52.5(11.1)$ & $52.7(10.2)$ \\
\hline Gender & $N$ & 106 & 69 \\
\hline Male & $n(\%)$ & $47(44.3)$ & $29(42.0)$ \\
\hline Female & $n(\%)$ & $59(55.7)$ & $40(58.0)$ \\
\hline \multirow[t]{2}{*}{ Weight $(\mathrm{kg})$} & $N$ & 103 & 66 \\
\hline & Mean $(\mathrm{SD})$ & $83.2(16.4)$ & $82.0(14.9)$ \\
\hline \multirow[t]{2}{*}{ BMI $\left(\mathrm{kg} / \mathrm{m}^{2}\right)$} & $N$ & 102 & 65 \\
\hline & Mean (SD) & $28.5(4.9)$ & $27.9(4.5)$ \\
\hline Diagnosis of psoriasis & $N$ & 106 & 69 \\
\hline Yes & $n(\%)$ & $82(77.4)$ & $55(79.7)$ \\
\hline No & $n(\%)$ & $24(22.6)$ & $14(20.3)$ \\
\hline \multirow[t]{2}{*}{ Time since initial PsA diagnosis (months) } & $N$ & 106 & 69 \\
\hline & Mean $(S D)$ & $87.1(92.8)$ & $88.6(94.8)$ \\
\hline \multirow[t]{2}{*}{$\leq 2$ years } & $n$ & 35 & 23 \\
\hline & Mean $(S D)$ & $10.0(5.5)$ & $10.1(5.0)$ \\
\hline \multirow[t]{2}{*}{$>2$ years } & $N$ & 71 & 46 \\
\hline & Mean $(\mathrm{SD})$ & $125.1(92.0)$ & $127.8(94.1)$ \\
\hline PsA prior treatment & $N$ & 106 & 69 \\
\hline Yes & $n(\%)$ & $105(99.1)$ & $68(98.6)$ \\
\hline No & $n(\%)$ & $1(0.9)$ & $1(1.4)$ \\
\hline \multicolumn{4}{|l|}{ Type of prior treatment (at least one) } \\
\hline csDMARDs & $n(\%)$ & $101(95.3)$ & $66(95.7)$ \\
\hline NSAIDs & $n(\%)$ & $43(40.6)$ & $25(36.2)$ \\
\hline Corticosteroids & $n(\%)$ & $34(32.1)$ & $18(26.1)$ \\
\hline bDMARDs & $n(\%)$ & $17(16.0)$ & $13(18.8)$ \\
\hline Other(s) & $n(\%)$ & $8(7.5)$ & $4(5.8)$ \\
\hline Professional status & $N$ & 105 & 68 \\
\hline Working & $n(\%)$ & $49(46.7)$ & $32(47.1)$ \\
\hline Number of sick leave days ${ }^{a}$ & $N$ & 48 & 32 \\
\hline 0 days & $n(\%)$ & $41(85.4)$ & $28(87.5)$ \\
\hline 3 days & $n(\%)$ & $2(4.2)$ & $0(0.0)$ \\
\hline 6 days & $n(\%)$ & $1(2.1)$ & $1(3.1)$ \\
\hline
\end{tabular}


Table 1 continued

\begin{tabular}{llll}
\hline Characteristic & & SAF $(\boldsymbol{N}=\mathbf{1 0 6})$ & REF $(\boldsymbol{N}=\mathbf{6 9})$ \\
\hline 7 days & $n(\%)$ & $1(2.1)$ & $1(3.1)$ \\
15 days & $n(\%)$ & $1(2.1)$ & $0(0.0)$ \\
20 days & $n(\%)$ & $1(2.1)$ & $1(3.1)$ \\
21 days & $n(\%)$ & $1(2.1)$ & $1(3.1)$ \\
Not working & $n(\%)$ & $56(53.3)$ & $36(52.9)$ \\
No established relationship to PsA & $n(\%)$ & $44(78.6)$ & $27(75.0)$ \\
Established relationship to PsA & $n(\%)$ & $12(21.4)$ & $9(25.0)$ \\
\hline
\end{tabular}

Unless otherwise stated, percentages or mean (SD) are calculated from the number of patients with non-missing data $n$ number of subjects with non-missing data, $B M I$ body mass index, $b D M A R D$ biologic disease-modifying anti-rheumatic drug, csDMARDs conventional synthetic disease-modifying anti-rheumatic drug, NSAID non-steroidal anti-inflammatory drug, $P S A$ psoriatic arthritis, $R E F$ reference set, SAF safety analysis set, $S D$ standard deviation

a Sick leave days due to PsA within the last 3 months before apremilast initiation

${ }^{\mathrm{b}}$ Percentages calculated from the number of patients not working

approximately three-quarters (15/21 [71.4\%]) achieved complete resolution at month 6 (Fig. 3). The findings observed in the SAF were similar to those of the REF (Fig. S2).

\section{Patient-Reported Outcomes}

Most patients in the REF (60/69 [87.0\%]) had a PsAID12 $>4$ at apremilast initiation, the cut-off value for patient-acceptable symptom state. In these patients, mean overall PsAID12 score and the mean scores of all 12 domains were lower at months 3 and 6 (Fig. 4 and Table S4). Of patients with PsAID12 $>4$ at baseline $(n=60)$, fewer than half $(27 / 60 \quad[45.0 \%])$ had a PsAID12 $>4$ at month 6 , and the mean (SD) global score decreased to 4.4 (2.1), compared with 6.3 (1.4) at apremilast initiation.

Similar reductions in mean global HAQ-DI were observed after apremilast initiation, indicating an improvement in patient's health status and their level of functional activity. Of 67 patients in the REF with an HAQ-DI recorded at apremilast initiation, $4.5 \%(3 / 67)$ had HAQDI $<0.5$ at apremilast initiation compared with $16.4 \%(11 / 67)$ at month 6; approximately half of all patients (35/67 [52.2\%]) achieved a reduction of at least 0.35 at month 6 . The mean
(SD) HAQ-DI global score decreased to $1.0(0.6)$ at month 6 from $1.5(0.6)$ at apremilast initiation. Furthermore, a reduction was observed for all HAQ-DI domains, suggesting a gradual and sustained improvement of functional activities and daily living (Fig. 5 and Table S4). For both PsAID12 and HAQ-DI, the trends observed in the SAF were similar to that of REF (Figs. S3 and S4).

\section{Safety}

Overall, 48 (45.3\%) patients in the SAF experienced at least one treatment-related TEAE; the most frequent were diarrhoea (20 [18.9\%] patients), nausea and headache (10 [9.4\%] patients each), followed by affective disorder, pruritus and weight loss (4 [3.8\%] patients each) (Table 2). All treatment-related TEAEs were assessed as non-serious and mild or moderate in severity, except for an event of tension headache that was assessed as severe. Overall, the observed treatment-related TEAEs aligned with the current apremilast safety profile [16]. 
(a)

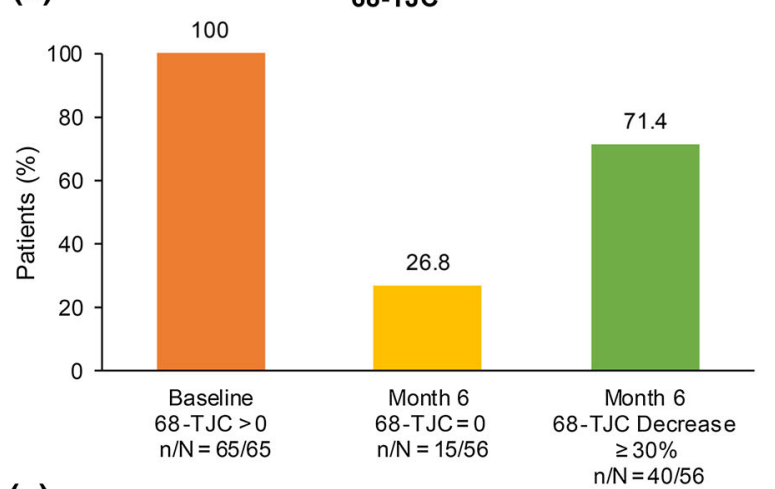

(c)

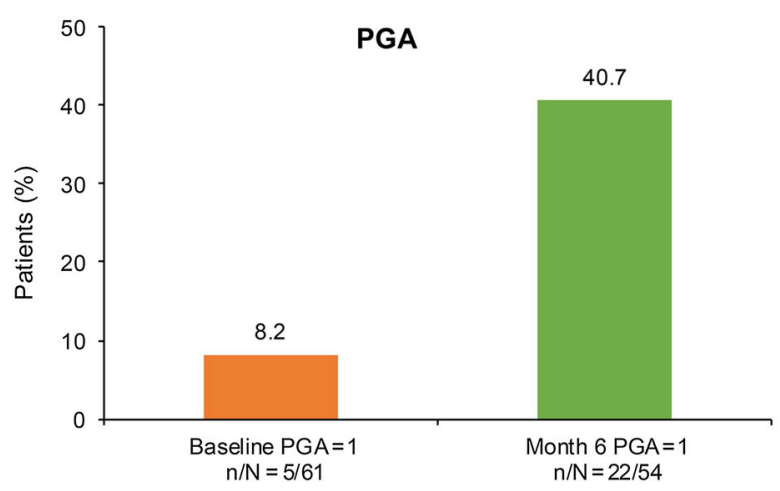

Fig. 2 Effect of apremilast on PsARC subscores at month 6 (REF). $n$ umber of patients with desired outcome of interest, $N$ number of patients with non-missing data available at that time point, 66-SJC 66-joint count for (b)

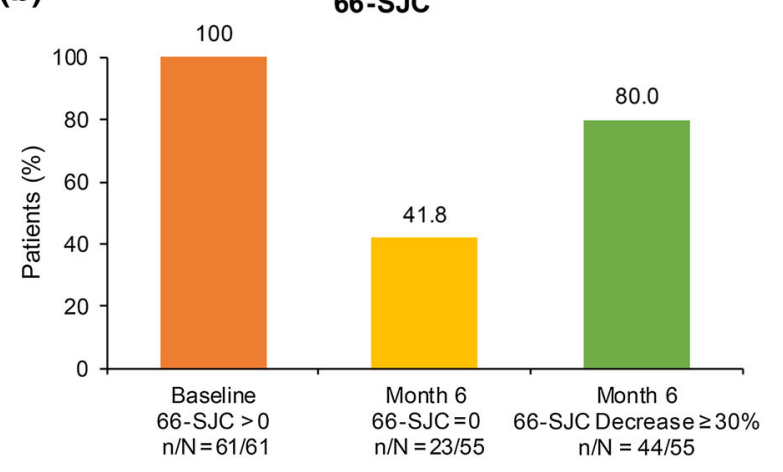

(d)

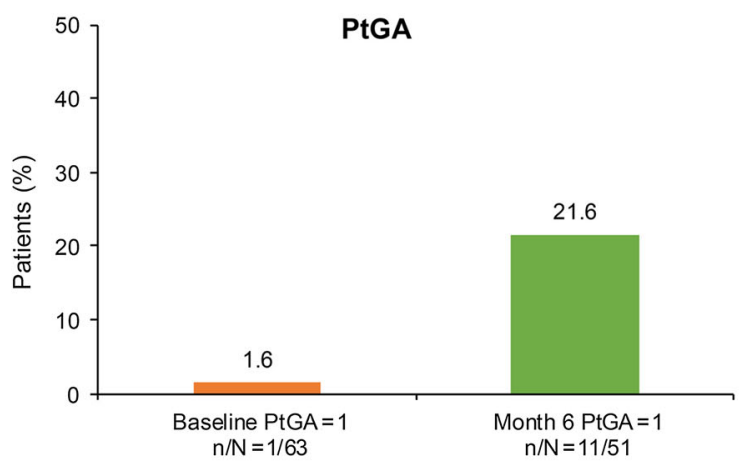

swelling, 68-TJC 68-joint count for pain/tenderness, PGA Physician Global Assessment, PsARC Psoriatic Arthritis Response Criteria, PtGA Patient Global Assessment, REF reference set (a)

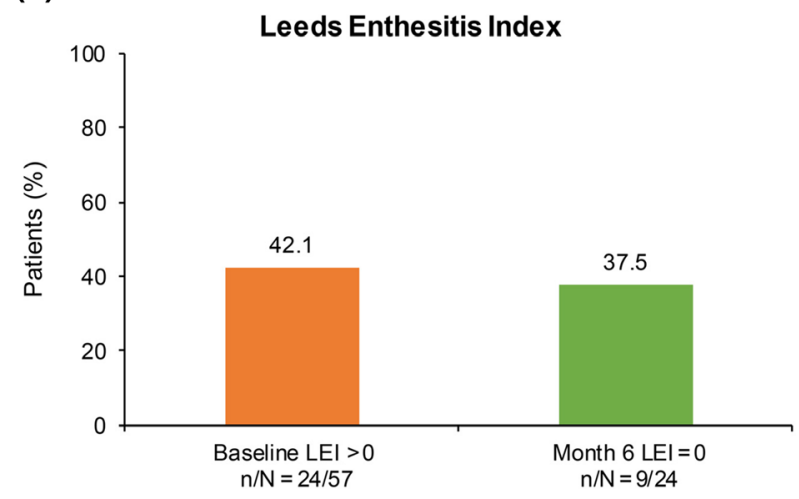

(b)

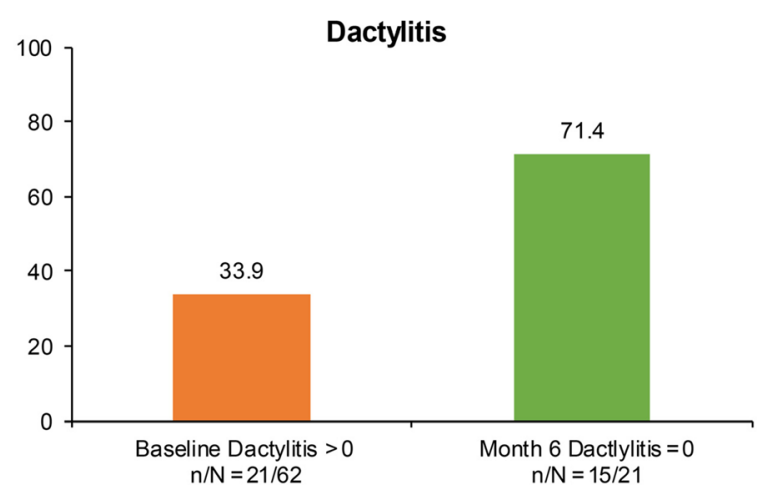

Fig. 3 Effect of apremilast on enthesitis and dactylitis at 6 months of treatment. $n$ number of patients with desired outcome of interest at specific time point, $N$ number of patients with non-missing data at that time point, LEI Leeds Enthesitis Index 
(a)

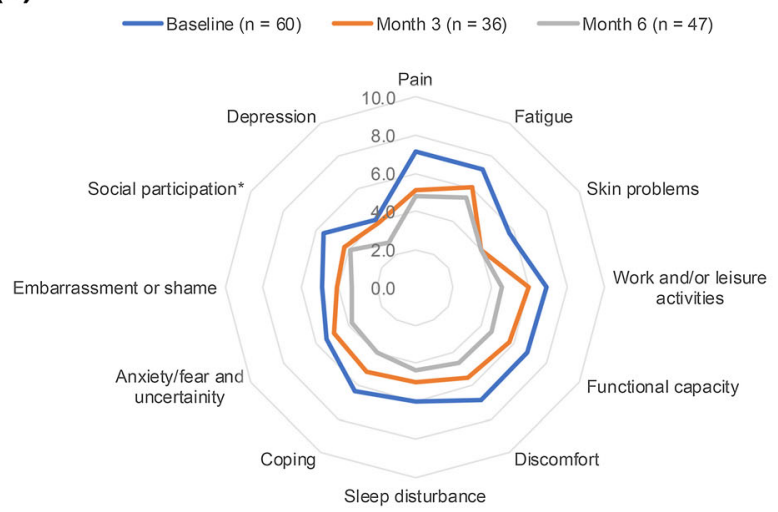

Fig. 4 Change in PsAID12 scores among patients with global score $>4$ at apremilast initiation: $\mathbf{a}$ individual scores and $\mathbf{b}$ overall score. ${ }^{*}$ Data were available for only 46 patients at 6 months for social participation domain.

(a)

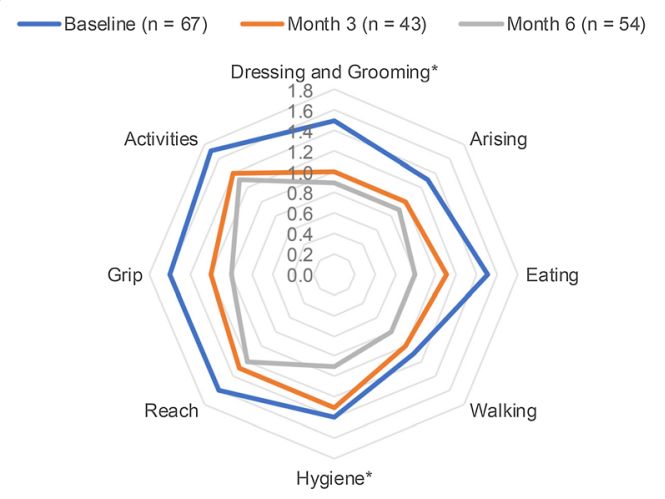

Fig. 5 Change in HAQ-DI: a individual scores and b overall score. ${ }^{*}$ Data were available for only 42 patients at month 3 for dressing and grooming and hygiene domains. $n$ number of subjects with non-missing data at each time

\section{DISCUSSION}

While the efficacy and safety of apremilast have been reported in long-term clinical trials, few studies have assessed the effectiveness and safety of apremilast in the routine treatment of patients with active PsA. The observational APOLO study was designed to appraise the realworld effectiveness and tolerability of apremilast in patients with active PsA treated in Belgium, from a patient and rheumatologist perspective. (b)

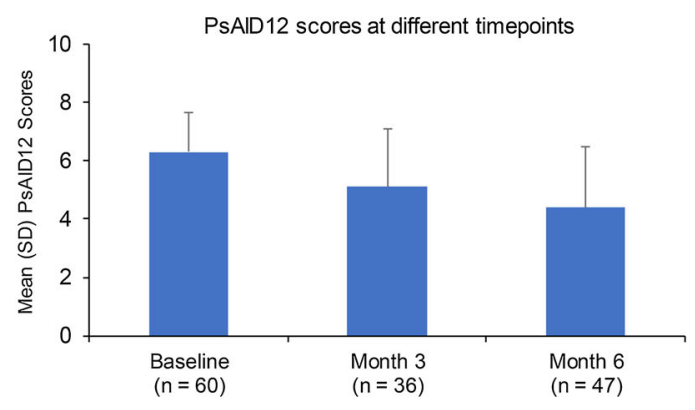

$n$ number of subjects with non-missing data at each time point. PsAID12 ranges from 0 to $10,10=$ worst health score. PsAID12 Psoriatic Arthritis Impact of Disease 12, REF reference set, SD standard deviation

(b)

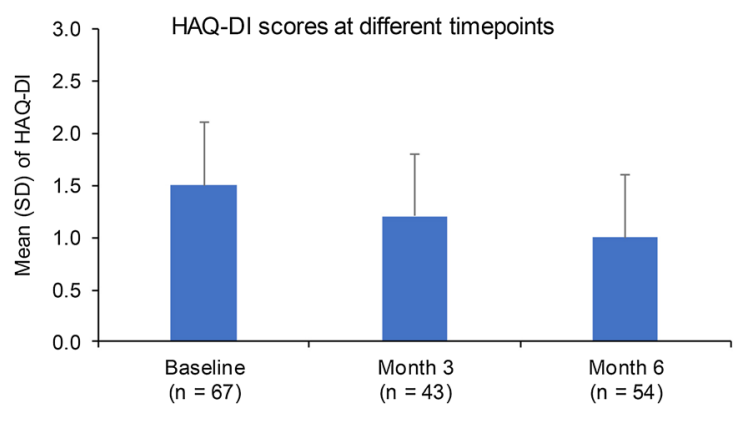

point. HAQ-DI ranges from 0 to $3: 0=$ no functional disability, $3=$ severe functional disability. HAQ-DI Health Assessment Questionnaire Disability Index, REF reference set, $\mathrm{SD}$ standard deviation

The effectiveness of apremilast was assessed using the PsARC, which is considered an acceptable primary outcome by the European Medicines Agency (EMA) [25]. After 6 months of treatment, the PsARC response indicated reduced inflammation, improvements in pain/tenderness and swelling in joints and an improvement in disease symptoms. This was accompanied by improvements in enthesitis and dactylitis, two important hallmarks of PsA.

PsA has a significant impact on the patient's physical function, energy level, social 
Table 2 Treatment-related TEAEs reported in more than $2 \%$ of patients

\begin{tabular}{ll}
\hline SOC & SAF \\
PT & N $=\mathbf{1 0 6}$ \\
\hline Patient with at least 1 treatment-related TEAE, $n$ (\%) & $48(45.3)$ \\
Gastrointestinal disorders, $n$ (\%) & $31(29.2)$ \\
Diarrhoea & $20(18.9)$ \\
Nausea & $10(9.4)$ \\
Nervous system disorders, $n$ (\%) & $17(16.0)$ \\
Headache & $10(9.4)$ \\
Migraine & $3(2.8)$ \\
Psychiatric disorders, $n$ (\%) & $11(10.4)$ \\
Affective disorder & $4(3.8)$ \\
Depressed mood & $3(2.8)$ \\
Skin and subcutaneous tissue disorders, $n$ (\%) & $5(4.7)$ \\
Pruritus & $4(3.8)$ \\
Investigations, $n$ (\%) & $4(3.8)$ \\
Weight decreased & $4(3.8)$ \\
General disorders and administration site conditions, $n(\%)$ & $3(2.8)$ \\
\hline
\end{tabular}

$P T$ preferred term, $S A F$ safety analysis set, $S O C$ system organ class, $T E A E$ treatment-emergent adverse event

participation, mood and quality of life. Therefore, a key element in the management of PsA is the patient's assessment of their disease status and the effectiveness of their treatment. In the APOLO study, PROs were used to capture the patients' global assessment, physical function and health-related quality of life, in addition to the physician's assessments.

Our data show that apremilast treatment had a positive impact on the patient's physical and psychological well-being after 6 months, as assessed either by the patient or by the physician. Specifically, using the PsAID questionnaire, patients reported an improvement in pain, skin problems and fatigue and also in functional capacity, social participation and discomfort. Furthermore, the physical impairment commonly faced by patients with PsA and assessed through the HAQ-DI appeared less pronounced following apremilast treatment. The results of the APOLO study are aligned with the efficacy of apremilast demonstrated in phase 3 PALACE 2-4 clinical trials [26-28] and in the observational, multicentre, prospective LAPIS-PsA study [29]. As assessed by the physician, over half $(56 \%)$ of patients in LAPIS-PsA had no or minimal PsA symptoms after approximately 4 months of apremilast treatment compared with $41 \%$ of patients in APOLO after 6 months of apremilast treatment. The proportion of patients achieving complete resolution of dactylitis was also similar in LAPISPsA and APOLO (28-67\% at month 4 in LAPISPsA and $71 \%$ at month 6 in APOLO), indicating a comparable, positive effect on joint diseases in the two studies. The proportion of patients achieving complete resolution of enthesitis was lower in APOLO (at 6 months) than in LAPISPsA (at approximately 4 months); however, the sample size for this outcome was notably smaller in APOLO. During the study, apremilast was well tolerated and the reported treatment- 
related TEAEs were in line with the most commonly reported AEs [16].

The main strength of APOLO is that it assesses the impact of apremilast treatment in patients with PsA in a real-world setting, from the perspectives of both the physician and the patient. The study has few limitations: (1) being an observational study, there was a relatively high number of missing data during the study; (2) the study was a single-arm study and was not designed to make comparisons or perform hypothesis testing; (3) PROs (PsAID12, HAQ-DI) are subjective and lead to large inter-individual variability in the observed data when analysing low numbers of patients.

\section{CONCLUSIONS}

The results from APOLO confirm that apremilast reduces PsA signs and symptoms across various domains and physical functions, improving patient's quality of life. Improvements were observed after 3 months of treatment and maintained or improved further for up to 1 year. Safety was consistent with the known safety profile.

\section{ACKNOWLEDGEMENTS}

We thank all the patients who participated in the APOLO study, as well as the investigators from each study centre and their collaborators.

Funding. This study was funded by Celgene. Amgen acquired the worldwide rights to Otezla $^{\circledR}$ (apremilast) on November 21, 2019. Amgen funded the journal's rapid service and open access fees.

Authorship. All named authors meet the International Committee of Medical Journal Editors criteria for authorship for this article, take responsibility for the integrity of the work as a whole, and have given their approval for this version to be published.

Author Contributions. Conceptualization: ANT, FVdB, KdV, M-JK, and RL. Methodology:
ANT, FVdB, KdV, M-JK, and RL. Formal analysis and investigation: ANT, FVdB, JV, KdV, M-JK, MVdB, PR, RL, and SDR. Writing-review and editing: ANT, FVdB, JV, KdV, M-JK, MVdB, PR, $\mathrm{RL}$, and SDR.

Medical Writing and Editorial Assistance. Roberta Farina, Caroline Montagner, and Marie-Anne Thil from Keyrus Life Science, funded by Amgen, provided support for data management, statistical analysis, writing of study protocol, and interim and final reports as well as the writing of this manuscript. Claire Desborough, Amgen (Europe) $\mathrm{GmbH}$, also provided medical writing support for this manuscript. We thank all the patients who participated in the APOLO study, as well as the investigators from each study centre and their collaborators.

Disclosures. Kurt de Vlam has received grant/research support and/or consultation fees from Celgene, Amgen, LEO Pharma, Eli Lilly, Galapagos, Novartis, Pfizer, and UCB; Adrien Nzeusseu Toukap has received speaker and consultancy fees and/or research grants from AbbVie, BMS, Celgene, Eli Lilly, Janssen, MSD, Novartis, Pfizer, and UCB; Silvana Di Romana has received research grants from Viatris; Filip Van den Bosch has received speaker and/or consultancy fees from AbbVie, Celgene, Eli Lilly, Galapagos, Gilead, Janssen, Merck, Novartis, Pfizer, and UCB; Rik Lories has received consultancy, speaker fees and research grants from AbbVie, Amgen, Boehringer-Ingelheim, Biosplice Therapeutics, Eli Lilly, Galapagos, Janssen, Kabi-Fresenius, MSD, Novartis, Pfizer, Sandoz, and UCB; Marie-Joëlle Kaiser, Johan Vanhoof, Philip Remans, and Marthe Van den Berghe have nothing to disclose.

Compliance with Ethics Guidelines. The study protocol was approved by the medical ethics committee of UZ Leuven and was conducted in accordance with the International Council for Harmonisation of Technical Requirements for Pharmaceuticals for Human Use Guideline for Good Clinical Practice, the guiding principles of the Declaration of Helsinki 1964, and its later amendments. Informed 
consent was obtained from all the subjects participating in this study.

Data Availability. The datasets generated during and/or analysed during the current study are available from the corresponding author on reasonable request. Qualified researchers may request data from Amgen clinical studies. Complete details are available at the following: https://www.amgen.com/science/ clinical-trials/clinical-data-transparencypractices/clinical-trial-data-sharing-request

Open Access. This article is licensed under a Creative Commons Attribution-NonCommercial 4.0 International License, which permits any non-commercial use, sharing, adaptation, distribution and reproduction in any medium or format, as long as you give appropriate credit to the original author(s) and the source, provide a link to the Creative Commons licence, and indicate if changes were made. The images or other third party material in this article are included in the article's Creative Commons licence, unless indicated otherwise in a credit line to the material. If material is not included in the article's Creative Commons licence and your intended use is not permitted by statutory regulation or exceeds the permitted use, you will need to obtain permission directly from the copyright holder. To view a copy of this licence, visit http://creativecommons.org/licenses/bync/4.0/.

\section{REFERENCES}

1. European Medicines Agency. Committee for Medicinal Products for Human Use. Guideline on clinical investigation of medicinal products for the treatment of psoriatic arthritis. 2006:1-10. https:// www.ema.europa.eu/en/documents/scientificguideline/guideline-clinical-investigationmedicinal-products-treatment-psoriatic-arthritis_ en.pdf. Accessed Aug 2021.

2. Gladman DD, Antoni C, Mease P, Clegg DO, Nash P. Psoriatic arthritis: epidemiology, clinical features, course, and outcome. Ann Rheum Dis. 2005;64(Suppl 2):ii14-7.
3. Lloyd P, Ryan C, Menter A. Psoriatic arthritis: an update. Arthritis. 2012;2012:176298.

4. Ogdie A, Weiss P. The epidemiology of psoriatic arthritis. Rheum Dis Clin N Am. 2015;41(4):545-68.

5. Gudu T, Gossec L. Quality of life in psoriatic arthritis. Expert Rev Clin Immunol. 2018;14(5): 405-17.

6. Barnas JL, Ritchlin CT. Etiology and pathogenesis of psoriatic arthritis. Rheum Dis Clin N Am. 2015;41(4):643-63.

7. Veale DJ, Fearon U. The pathogenesis of psoriatic arthritis. Lancet. 2018;391(10136):2273-84.

8. Mease PJ. Psoriatic arthritis-update on pathophysiology, assessment, and management. Bull NYU Hosp Jt Dis. 2010;68(3):191-8.

9. Belasco J, Wei N. Psoriatic arthritis: what is happening at the joint? Rheumatol Ther. 2019;6(3): 305-15.

10. Gladman DD, Farewell VT, Wong K, Husted J. Mortality studies in psoriatic arthritis: results from a single outpatient center. II. Prognostic indicators for death. Arthritis Rheum. 1998;41(6):1103-10.

11. Horreau C, Pouplard C, Brenaut E, et al. Cardiovascular morbidity and mortality in psoriasis and psoriatic arthritis: a systematic literature review. J Eur Acad Dermatol Venereol. 2013;27(Suppl 3): $12-29$.

12. Martin BC, Thomas LW, Dann FJ. Apremilast for the treatment of psoriatic arthritis. Dermatol Online J. 2017;23(2):13030/qt36n2k4jw.

13. Mease PJ. Apremilast: a phosphodiesterase 4 inhibitor for the treatment of psoriatic arthritis. Rheumatol Ther. 2014;1(1):1-20.

14. Poole RM, Ballantyne AD. Apremilast: first global approval. Drugs. 2014;74(7):825-37.

15. Schett G, Sloan VS, Stevens RM, Schafer P. Apremilast: a novel PDE4 inhibitor in the treatment of autoimmune and inflammatory diseases. Ther Adv Musculoskelet Dis. 2010;2(5):271-8.

16. European Medicines Agency. Otezla: Summary of Product Characteristics. 2019:1-41. https://www. ema.europa.eu/en/documents/productinformation/otezla-epar-product-information_en. pdf.

17. Coates LC, Kavanaugh A, Mease PJ, et al. Group for research and assessment of psoriasis and psoriatic arthritis 2015 treatment recommendations for 
psoriatic arthritis. Arthritis Rheumatol. 2016;68(5): 1060-71.

18. Gossec L, Coates LC, de Wit M, et al. Management of psoriatic arthritis in 2016: a comparison of EULAR and GRAPPA recommendations. Nat Rev Rheumatol. 2016;12(12):743-50.

19. Coates LC, Soriano E, Corp N, et al. OP0229 The Group for Research and Assessment of Psoriasis and Psoriatic Arthritis (GRAPPA) treatment recommendations 2021. Ann Rheum Dis. 2021;80(Suppl 1): 139-40.

20. Orbai AM, Ogdie A. Patient-reported outcomes in psoriatic arthritis. Rheum Dis Clin N Am. 2016;42(2):265-83.

21. The reimbursement criteria for Otezla in psoriasis in Belgium. https://ondpanon.riziv.fgov.be/ SSPWebApplicationPublic/fr/Public/ProductSearch. Accessed Aug 2021.

22. Wong PC, Leung YY, Li EK, Tam LS. Measuring disease activity in psoriatic arthritis. Int J Rheumatol. 2012;2012:839425.

23. Gossec L, de Wit M, Kiltz U, et al. A patient-derived and patient-reported outcome measure for assessing psoriatic arthritis: elaboration and preliminary validation of the Psoriatic Arthritis Impact of Disease (PsAID) questionnaire, a 13-country EULAR initiative. Ann Rheum Dis. 2014;73(6):1012-9.

24. Janssens X, Decuman S, De Keyser F, Belgian Rheumatoid Arthritis Disability Assessment Study Group. Assessment of activity limitations with the health assessment questionnaire predicts the need for support measures in patients with rheumatoid arthritis: a multicenter observational study. PLoS ONE. 2014;9(9):e106749.

25. Mease PJ. Measures of psoriatic arthritis: Tender and Swollen Joint Assessment, Psoriasis Area and Severity Index (PASI), Nail Psoriasis Severity Index (NAPSI), Modified Nail Psoriasis Severity Index
(mNAPSI), Mander/Newcastle Enthesitis Index (MEI), Leeds Enthesitis Index (LEI), Spondyloarthritis Research Consortium of Canada (SPARCC), Maastricht Ankylosing Spondylitis Enthesis Score (MASES), Leeds Dactylitis Index (LDI), Patient Global for Psoriatic Arthritis, Dermatology Life Quality Index (DLQI), Psoriatic Arthritis Quality of Life (PsAQOL), Functional Assessment of Chronic Illness Therapy-Fatigue (FACIT-F), Psoriatic Arthritis Response Criteria (PsARC), Psoriatic Arthritis Joint Activity Index (PsAJAI), Disease Activity in Psoriatic Arthritis (DAPSA), and Composite Psoriatic Disease Activity Index (CPDAI). Arthritis Care Res (Hoboken). 2011;63(Suppl 11):S64-85.

26. Cutolo M, Myerson GE, Fleischmann RM, et al. A phase III, randomized, controlled trial of apremilast in patients with psoriatic arthritis: results of the PALACE 2 trial. J Rheumatol. 2016;43(9):1724-34.

27. Edwards CJ, Blanco FJ, Crowley J, et al. Apremilast, an oral phosphodiesterase 4 inhibitor, in patients with psoriatic arthritis and current skin involvement: a phase III, randomised, controlled trial (PALACE 3). Ann Rheum Dis. 2016;75(6):1065-73.

28. Wells AF, Edwards CJ, Kivitz AJ, et al. Apremilast monotherapy in DMARD-naive psoriatic arthritis patients: results of the randomized, placebo-controlled PALACE 4 trial. Rheumatology (Oxford). 2018;57(7):1253-63.

29. Wollenhaupt J, Bach C, Roemmler-Zehrer J. Effectiveness and safety of apremilast in biologic-naive versus biologic-experienced patients with psoriatic arthritis in real-world clinical practice settings in Germany: Interim analysis of an ongoing, multicenter, prospective, non-interventional study [abstract]. Arthritis Rheumatol. 2020;72(suppl 10). https://www.acrabstracts.org/abstract/ effectiveness-and-safety-of-apremilast-in-biologicnaive-versus-biologic-experienced-patients-withpsoriatic-arthritis-in-real-world-clinical-practicesettings-in-germany-interim-analysis-of-an-ongoi/. Accessed 5 Aug 2021. 